\title{
Empirical Analysis of the Difference of the Luxury Consumption Motivations between Chinese and British
}

\author{
Li-Hua WANG ${ }^{1, a,{ }^{*},}$, Qian ZHAO ${ }^{2, b}$ \\ ${ }^{1}$ School of Economics, Hebei University (071002) No.180 Wusidong Road. Baoding City, Hebei \\ Province, China \\ ${ }^{2}$ De Montfort University, U.K. \\ aolica_w@163.com, bmaohuhuq@yeah.net \\ ${ }^{*}$ Corresponding author
}

Keywords: Purchasing Motivations, Personal Motivation, Social Motivation.

\begin{abstract}
This research aims to find out the purchasing motivations of luxury in China and Britain, and the difference between them using empirical analysis. Questionnaire for young people was used in this research to get the basic data in the two markets, and found 8 motivations: Quality/Hedonic, Self-gift Giving, Investment, Impulse/conformity, Snob/Status, Gifts, Reference Group, Conspicuous/Veblen. In which, there are 4 motivations have significant difference in the two nations including snob/status, impulse/conformity, quality/hedonic, and reference group. All of these motivations influence the purchasing selection in the two markets, but often have different meaning in different market.
\end{abstract}

\section{Introduction}

China and Britain both play important role in the global luxury market. China is an emerging luxury market, but having been the largest consumption country [1] while Britain is one of the main traditional markets. So what have affected the consumers' purchasing behavior can be found through studying these two markets representing developing world and developed world representatively.

There are many experts have researched luxury consumption motivations. Veblen mentioned conspicuous motivation[2]; Leibenstein put forward snob motivation[3]; Dubois and Laurent developed hedonic value[4]; Wong promoted the gift motivation[5]; Vigneron and Johson developed the idea of social motivations including veblen, snob, bandwagon and personal motivations including hedonist and perfectionist[6]; Tsai focused on the personal motivation, thought self-pleasure, self-gift giving, quality and congruity with internal self are the main personal motivations[7]. Until now, there have been 8 motivations including 4 social motivations and 4 personal motivations found. Some Chinese experts studied the motivations in China and get the similar purchasing motivations in Chinese market. $[8,9,10]$

But after all, China is an emerging market and Britain is a traditional market with a long luxury consuming history. Besides, China is an oriental country and Britain is a western country, these two countries have different culture back, social model and income level, these may lead to different understanding for the purchasing motivations and result in different selection in the two markets. So this research aims to find out the purchasing motivations of luxury in China and Britain, and the difference between them using empirical analysis method.

\section{Methodology}

\section{Data Collection}

Questionnaire has been used in this research to find what the younger in China and Britain are thinking about luxury. The questionnaire was developed with reference to the research in Impact of Personal Orientation on Luxury Brand Purchase value: An International Investigation [11] and The Attitudes underlying Preferences of Young Urban Educated Polish Consumers towards Products 
Made In Western Countries [12]. In this questionnaire, Likert Scale that is five-point scale (from strongly disagree to strongly agree) was used. After in-depth interviews and pre-tested, the final versions of the questionnaire was made including 25 items to test the difference of the two nations in 8 motivations which are snob, conspicuous, gifts, reference group, impulse, quality, investment, self-gift giving, of which the former four motivations are social motivations and the later four are personal motivations.

\section{Sample Explanation}

The sample of the study is a non-probabilistic convenience sample. The respondents were asked to fill the questionnaire on line. In order to avoid the misunderstanding caused by translation, we prefer to use the English version. In China, 425 copies of questionnaires come back. Among them, 371 copies are valid. $43.9 \%$ of the respondents are males. Respondents are divided into two age groups: the first group (between 20 and 25) represents $54.0 \%$ of the sample, and the second group (between 26 and 30) accounts for $46.0 \%$ of the sample. The majority of the respondents (73.4\%) have an average income below $3000 \mathrm{RMB}$ per month. This is because the sample is the young people and most of them are still students, about $61 \%$ is the student in college or university. Therefore, the majority of the respondents have limited income level. In UK, 328 copies are valid. $54 \%$ of the respondents are males. Respondents are divided into two age groups: the first group (between 20 and 25) represents $38.0 \%$ of the sample, and the second group (between 26 and 30) constitutes $62.0 \%$ of the sample. In Britain, the salary question was not mentioned, for the question was an important privacy in Britain. But in UK, many respondents have graduated from colleges which have two years studying time. So the average income in Britain should be higher than in China.

The samples surveyed aimed at the young people (aged from 20 to 30) in two countries for three main reasons. Firstly, the samples are relatively homogeneous in terms of demographics, social background, and education. The data collected have strong comparability. Secondly, compared with old people, young people are more able to read and speak English, which will reduce the misunderstanding caused by translating. Finally, according to the experts' suggestion, the luxury consumer is becoming younger, so young people are likely to be actual or potential customers of luxury products in the future. They represent the future luxury consumption trend.

\section{Research Limitations}

For some reasons expressed earlier, this research made the sample from people aged from 20 to 30 years old. In fact, the young people have limited purchasing power, many responders are students. Although some of them can get some income, but the wealth of themselves cannot afford to the luxury. So many of them have no experience to buy luxury independent even some people are enjoying luxury getting from others as gifts. So to some extent, the survey result cannot reflect the real situation in China.

Secondly, the questionnaire was issued on line, so responders maybe come from any city of China. But at present, the income gap of people in different city is very big; people come from different income level must have the different idea on luxury. This may affect the reliability of the result.

Thirdly, the object of this research is all kinds of luxury brand accepted by global market. Some experts have suggested that if the research aims at some kind of the luxury, for example handbag, the research may have a better target, and have a better result.

Fourthly, this research did not analyze the influence of grander, income, education on the motivation respectively. But all of these should play an important role on motivation.

\section{Finding and Discussion}

SPSS was used to examine the internal connection between these items and motivations by factor analysis. At first, KMO and Bartlett's Test using SPSS13.0 examined the reliability and validity of the data. Then the component of the motivation should be looked for using varimax 
rotation. At last Independent Samples T-Test was used to find the deference of the motivations between Chinese and British.

\section{The Reliability Test of the Sample}

According to Kaiser's theory, the data is suitable for factor analysis when the KMO value is bigger than 0.5. The KMO value of this sample is 0.798 (see table 1), bigger than 0.5 , which means that the data is suitable for factor analysis. The P value in the Bartlett's Test of Sphericity is close to 0 , which is less than 0.001, and the Cronbach's Alpha value of all the items is 0.831 (see table 1), so the sample data has a high reliability.

Table1 KMO, Bartlett's Test and Reliability Statistics of the Whole Data

\begin{tabular}{ccccccc}
\hline $\begin{array}{c}\text { Kaiser-Meyer-Olkin Measure } \\
\text { of Sampling Adequacy }\end{array}$ & \multicolumn{2}{c}{ Bartlett's Test of } & Sphericity & \multicolumn{2}{c}{ Reliability Statistics } \\
\cline { 2 - 6 } & Approx.Chi-Square & Df & Sig. & $\begin{array}{c}\text { Cronbach's } \\
\text { Alpha }\end{array}$ & $\begin{array}{c}\text { N of } \\
\text { Items }\end{array}$ \\
\hline 0.798 & 2398.597 & 320 & 0.000 & 0.831 & 25 \\
\hline
\end{tabular}

\section{The Component of Motivations}

After the reliability test, the component of the motivation should be looked for using varimax rotation. According to varimax rotation method, factor whose eigenvalue is bigger than 1 with reference to screeplot should be maintained, and when the component value is above 0.5 , this component is valid to the factor. Here the factor is the purchasing motivation; component is item of the questionnaire. So the table 2 arranges the components and motivations according to the component value, and indicated the valid component in red words. For example, the component value of item 14 is 0.805 for motivation 1 that is snob, but less than 0.5 for other motivations, so it is one of the items of snob, not other motivations. Other items have a same analyze way.

Based on factor analysis, this research got eight factors, which the component value is above 0.5 (see table 2): The first factor named as snob/status, is composed of by item 4, 13, 14, 15. The second factor named as conspicuous/veblen, is composed by item 1,2,3. The third factor named as impulse/conformity, is composed by item 18, 19, 20, 21. The fourth factor named as quality/hedonic, is composed by item $5,7,8,9,10$. The fifth factor named as investment, is composed of 2 items - item 16, 17. The sixth factor is named as gifts composed by item 11, 12. The seventh factor, which is named as self-gift giving, is composed by item 24,25 . The eighth factor, which is named as reference group, is composed by item 22, 23. The value of item 6 is different from other items. It has two value bigger than 0.5 , that is this item loads on the two factors, that is it loads on both factor 1 and factor 3 , it was set aside.

Until now, the eight motivations were found, but there is difference with the original views at the beginning of this paper that was concluded from the literatures. This research adjusted the motivations according to the in-depth interviews, some old motivations were combined, for example the quality and hedonic become quality, and the quality factor become more important; and two new motivations were put forwarded that is investment and reference group. And using factor analysis the eight new motivations were proved. Here, the four motivations -quality/hedonic, self-gift giving, investment, and impulse/conformity - are personal motivation; others - snob/status, gifts, reference group, conspicuous/veblen - are social motivations. 
Table 2 Rotated Component Matrix of the Whole Data

\begin{tabular}{|c|c|c|c|c|c|c|c|c|}
\hline & \multicolumn{8}{|c|}{ Component } \\
\hline & (1) & (2) & (3) & (4) & $(5)$ & (6) & (7) & (8) \\
\hline ITEM14 & .805 & .150 & .059 & .131 & .251 & .048 & .101 & .127 \\
\hline ITEM13 & .743 & .045 & .150 & .172 & .071 & .078 & .131 & -.003 \\
\hline ITEM15 & .731 & .206 & .265 & .110 & .048 & -.032 & .127 & .038 \\
\hline ITEM04 & .501 & .222 & .038 & .123 & .158 & .154 & .114 & .225 \\
\hline ITEM02 & .210 & .838 & .068 & .004 & -.051 & .016 & .047 & -.012 \\
\hline ITEM01 & .149 & .826 & .074 & -.102 & .052 & -.042 & .084 & .104 \\
\hline ITEM03 & .157 & .794 & .111 & .075 & .091 & -.024 & -.035 & .008 \\
\hline ITEM18 & .169 & .127 & .760 & .062 & .166 & .084 & .064 & .191 \\
\hline ITEM20 & .141 & .073 & .747 & -.086 & -.140 & .190 & .006 & .009 \\
\hline ITEM19 & .071 & .201 & .704 & .093 & .181 & -.025 & 197 & .167 \\
\hline ITEM21 & .168 & -.037 & .526 & .026 & -.243 & -.060 & .049 & .137 \\
\hline ITEM07 & .138 & -.006 & -.053 & .746 & -.148 & .130 & .114 & .170 \\
\hline ITEM08 & .090 & -.026 & .033 & .741 & -.017 & .005 & .031 & -.129 \\
\hline ITEM10 & .173 &. .118 & .073 & .684 & .095 & -.098 & -.011 & .093 \\
\hline ITEM09 & -.092 & .327 & .166 & .547 & .228 & -.093 & -.037 & -.259 \\
\hline ITEM05 & .239 & .142 & .207 & .433 & -.026 & -.072 & .110 & .339 \\
\hline ITEM25 & .166 & .028 & -.029 &. .018 & .835 & .168 & -.035 & .087 \\
\hline ITEM24 & .271 & .070 & -.012 & .028 & .802 & .075 & .108 & .094 \\
\hline ITEM11 & .063 & ..019 & .101 & .007 & .137 & .855 & .083 & -.069 \\
\hline ITEM12 & .064 &. .038 & .045 & -.034 & .088 & .839 & .058 & .170 \\
\hline ITEM22 & .075 & .059 & .133 & .072 & .052 & .041 & .831 & .087 \\
\hline ITEM23 & .177 & .019 & .095 & .053 & .011 & .102 & .813 & -.078 \\
\hline ITEM17 & -.057 & .010 & .250 & .062 & .114 & .026 & -.031 & .765 \\
\hline ITEM16 & .241 & .044 & .217 & -.038 & .065 & .091 & .024 & .726 \\
\hline ITEM06 & .512 & .323 & .503 & .034 & .104 & -.020 & -.298 & -.042 \\
\hline $\begin{array}{c}\text { Ariance } \\
\text { explained [\%] }\end{array}$ & 10.483 & 9.814 & 9.268 & 8.748 & 6.917 & 6.458 & 6.416 & 6.308 \\
\hline Cronbach's Alpha & .785 & .822 & .717 & .656 & .794 & .697 & .674 & .598 \\
\hline
\end{tabular}

\section{The Difference between the Two Nations}

The Independent Samples T Test should be used to get that whether the eight motivations have similar influence on the two nations, and what motivations have difference influence.

In this $\mathrm{T}$ test, the result was reached by two steps. The first step is the $\mathrm{F}$ test of 'Equal variances assumed'. From table 3, the F-value and P-value explain that there are significant differences on 4 factors in the two nations, including snob/status, impulse/conformity, quality/hedonic, and reference group; other factors of the two nations have no significant gaps. For example the F-value of snob is 6.029 and its $\mathrm{P}$-value is 0.017 , the P-value is smaller than 0.05 , so there is significant difference on snob's variances between the two nations. Impulse/conformity, quality/hedonic, and reference group have the similar results as snob.

The second step is the T test of 'Equal variances not assumed'. According to the first step, there is significant difference on snob's variances between the two nations. From table 3, the T-value of snob in the second step is 2.798 and the P-value is 0.006. Its T-value is larger than 2 and $\mathrm{P}$-value is smaller than 0.05 , so there is significant difference on snob's mean between the two nations. Impulse/conformity, quality/hedonic, and reference group have the similar results as snob. 
Table 3 Independent Samples T-Test

\begin{tabular}{|c|c|c|c|c|c|c|c|c|}
\hline & & \multicolumn{2}{|c|}{$\begin{array}{l}\text { Levene'STestforEqu } \\
\text { alityof Variances }\end{array}$} & \multicolumn{5}{|c|}{ T-test for Equality of Means } \\
\hline & & & Sig & $\mathrm{t}$ & df & $\begin{array}{l}\text { Sig } \\
\text { (2-tailed) }\end{array}$ & $\begin{array}{l}\text { Mean } \\
\text { Difference }\end{array}$ & $\begin{array}{l}\text { Std.Error } \\
\text { Difference }\end{array}$ \\
\hline \multirow{2}{*}{$\begin{array}{l}\text { Snob/ } \\
\text { Status }\end{array}$} & Equalvariances assumed & 6.029 & .017 & 3.301 & 320 & .001 & .440 & .137 \\
\hline & Equal Variances not assumed & & & 2.798 & 62.077 & .006 & .439 & .162 \\
\hline \multirow{2}{*}{$\begin{array}{l}\text { Conspicuo-us/Veb } \\
\text { len }\end{array}$} & Equal variances assumed & 3.983 & .042 & -.441 & 320 & .659 & -.071 & .161 \\
\hline & Equal Variances not assumed & & & -.394 & 62.976 & .705 & -.070 & .169 \\
\hline \multirow{2}{*}{$\begin{array}{l}\text { Impulse/ } \\
\text { conformity }\end{array}$} & Equal variances assumed & .059 & .812 & 4.402 & 320 & .002 & .591 & .135 \\
\hline & Equal Variances not assumed & & & 4.37 & 68.901 & .001 & .587 & .134 \\
\hline \multirow{2}{*}{$\begin{array}{l}\text { Quality/ } \\
\text { Hedonic }\end{array}$} & Equal variances assumed & 1.401 & .253 & 2.698 & 320 & .007 & .259 & .096 \\
\hline & Equal Variances not assumed & & & 2.432 & 63.016 & .018 & .261 & .097 \\
\hline \multirow{2}{*}{ Investment } & Equal variances assumed & .594 & .419 & -3.013 & 320 & .021 & -.361 & .153 \\
\hline & Equal Variances not assumed & & & -3.030 & 67.009 & .019 & -.362 & .157 \\
\hline \multirow{2}{*}{ Gifts } & Equal variances assumed & .009 & .901 & -1.784 & 320 & .056 & -.289 & .149 \\
\hline & Equal Variances not assumed & & & 1.875 & 69.627 & .055 & -.288 & .151 \\
\hline \multirow{2}{*}{ self-gift Giving } & Equal variances assumed & 9.702 & .003 & .719 & 320 & .087 & .275 & .162 \\
\hline & Equal Variances not assumed & & & 2.186 & 90.061 & .032 & .275 & .137 \\
\hline \multirow{2}{*}{ Reference Group } & Equal variances assumed & 3.307 & .069 & 6.109 & 320 & .001 & .791 & .153 \\
\hline & Equal Variances not assumed & & & 5.582 & 63.761 & .001 & .792 & .15 \\
\hline
\end{tabular}

So the result indicated that the differences of the motivations between the two nations are significant in four aspects: snob/status, impulse/conformity, quality/hedonic and reference group. In other motivations, the differences are not so obvious.

\section{The Reasons of Difference}

This research found there are four motivations have significant difference in the two market, and find the reasons of the difference.

\section{Snob/Status}

The consumers in both countries pay great attention to Snob and Status, but the snob in two markets are different. The snob motivation occurs in two circumstances. The first is the view of Vigneron and Johnson: 'when a new prestige product is launched, the snob will adopt the product first to take advantage of the limited number of consumers at that moment' ${ }^{[13]}$, the second is the view of Mason: 'snob effect is in evidence when status sensitive consumers come to reject a particular product as and when it is seen to be consumed by the general mass of people ${ }^{\text {,[14] }}$. In Britain market the snob motivation often occurs in the second circumstance. The consumers acquire the status through being different from others. On the contrary, snob motivation mainly occurs in the first circumstance in Chinese market, and the status needs to be accepted by the public. The different manifestations of this motivation in different nation should be noticed. And according to the interview to the experts, the British young people are playing more attentions to the snob motivation now. For the young group, the reason of occurring snob motivation should be noticed. It is very important in both two markets.

\section{Impulse/Conformity}

There are four items related to this motivation in the questionnaire. The responds from informant could explain the difference impact on these two markets by this motivation. For the item 'I cannot control myself to buy luxury goods when I see other people buy them', there are $21.03 \%$ Chinese agree with this view, of which $2.58 \%$ is extremely agree, but only $1.02 \%$ in Britain is agree and nobody extremely agree. It is similar for the item 'I often buy luxury goods on impulse', there are $29.15 \%$ agree and $8.12 \%$ extremely agree in China while $16.15 \%$ agree and $4.03 \%$ extremely agree 
in Britain. Other two items have similar results. This explained that Chinese consumers are more non-rationality than Britain, and they are easier to be influenced by others, and more impulse. So although impulse is valid in both markets, there is obviously different effect in fact and this has been verified by the result of independent samples T-Test.

\section{Quality/Hedonic}

There are different meanings but close relations between quality and hedonic. Quatily focuces on the visible aspects of the products while hedonic pay more attention to the invisible aspects. But in some ways, quality is positively correlated with the hedonic feeling. Better quality always related with better functions, better culture or longer history and so on. British have better understand to the culture implication of the products and enjoy the pleasure from the products culture. But Chinese consumers often combine the Quality and Hedonic motivations. That is why this research put these two motivations together. Chinese luxury market is at the beginning stage. The luxury brands focus on the promotion of their superb quality when enter into Chinese market. So quality becomes the most important one in Chinese consumers' mind and think good quality is the first thing in selecting goods and good quality can bring better feeling. More than $60 \%$ respondents accept this motivation. The Chinese consumers are just getting familiar with the luxury products, so at this stage, they can only accept the tangible aspects of the products. They still need more time to accept the intangible aspects, such as connotation, and understand the representative meaning behind the products.

\section{Reference Group}

Reference group shows the influence from other people, it is similar with the motivation conformity. But there are some significant differences between them. Conformity is a social motivation obviously, with which the consumer buy the luxury just in order to consistent with others. But reference group has some personal characteristics, with which the reference group just gives the consumer some suggestion or self view on some products, the consumer should do the choice independently. So the influence comes from the reference group maybe different with conformity. British trend to the personal characteristics. But until now, many Chinese consumers have little idea about luxury products, they just buy goods with reference to their friends. That is Chinese is inclined to the social characteristics. In one words, reference group is important in both two markets, but has different influence in different country.

\section{Conclusion}

\section{Main Results}

According to the western experts, there are two kinds of motivations for the luxury. One is social motivations including conspicuous/veblen, bandwagon/conformity, gifts and snob/status; the other is personal motivations including quality assurance, self-directed pleasure/hedonic, self-gift giving and congruity with internal self. Chinese experts believed there are social motivations and personal motivations in Chinese market similar with the western motivations.

This research planned to examine the purchasing motivation of luxury in China and Britain. In the process of survey, investment and reference group were found, and other motivations were adjusted with reference to the reality. At last, the consumption motivations in this research included snob/status, conspicuous/veblen, impulse/conformity, quality/hedonic, investment, reference group, gifts, self-gift giving, of which investment and reference group are new motivations.

But there are different understand and then different influence for the same motivations in the different markets. This research pointed out that the differences of the motivations between the two nations are significant in four aspects: snob/status, impulse/conformity, quality/hedonic and reference group. In other motivations, the differences are not so obvious.

\section{Managerial Implications}

According to the finding, this research promoted some implications for the luxury companies. Firstly, this research found that some motivations could be affected by other factors, such as 
cultural background. For example, Chinese consumers pay more attention to the relationship with other people influenced by the traditional cultural. So the social motivation is more significant in China than in Britain. But this cultural background plays a role not only in the social motivation but also in the personal motivation. So when the personal motivations appear in China, they are affected by the social motivations to some extent. So, the personal motivations in Chinese market have different meanings from western markets. For example, this paper gave the different meaning of hedonic motivation with other research for its different understanding in Chinese market. So, luxury companies should understand the history and cultural background, then analyze the purchasing motivation under this background before they want to enter into a new market.

Secondly, some motivations are valid motivations for a long time, such as conspicuous and snob. In both Chinese market and British market, they have been important in a very long time and should be significant in future. And in Chinese markets, as the newly luxury market, snob is more important than in Britain market. So, luxury companies should make a suitable price to explain their goods can give the consumers snob.

\section{Reference}

[1] Information on http://www.bain.com.cn

[2] Veblen, B. Thorstein, The Theory of the Leisure Class: An Economic Study in the Evolution of Institutions, Macmillan, New York, 1899, pp. 57-59

[3] H. Leibenstein, Bandwagon, snob, and Veblen effects in the theory of consumer demand, Quarterly Journal of Economics, Vol. 64(1950) 183-207

[4] Dubois, Bernard \&Laurent, Gilles, Attitudes Toward the Concept of Luxury: An Exploratory Analysis, Asia-Pacific Advances in Consumer Research, Siew Meng Leong and Joseph A. Cote(eds. ), Singapore, (1994) 273-278.

[5] Wong N.Y. and Ahuvia A.C., Personal Taste and Family Face: Luxury Consumption in Confucian and Western Societies, Journal of Psychology and Marketing, Vol.15 (1998), No. 5, pp 423-441

[6] Vigneron, Franck \& Johnson, Lester W. A Review and a Conceptual Framework of Prestige - Seeldng Consumer Behavior, Academy of Marketing Science Review, 3(1999)237-261.

[7] Sh.Tsai, Impact of personal orientation on luxury-brand purchase value-An international investigation, International Journal of Marketing Research, 47 (2005) 429-454.

[8] H. Wang, Explore the Chinese luxury consumer-related issues based on analysis of consumer behavior, Enterprise Economy, 5 (2009) 84-87.

[9] M. M. Gao, New Luxury Consumption Motivation of the Middle Class, Commercial Times, 12 (2009) 24-35.

[10] X. Zhu, An Empirical Research on Luxury Consumption Motives of Chinese Consumers, Business Economics and Administration, 3 (2006) 42-48.

[11] Sh.Tsai, Impact of personal orientation on luxury-brand purchase value-An international investigation, International Journal of Marketing Research, 47 (2005) 429-454.

[12] J. S. Marcoux, P. Filiatrault, E.Cheron, The Attitudes underlying Preferences of Young Urban Educated Polish Consumers towards Products Made In Western Countries, Journal of International Consumer Marketing, 9(1997), 5-29. 